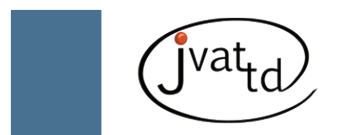

\title{
Technetium-99m-labeled deoxynivalenol from Fusarium mycotoxin alters organ toxicity in BALB/c mice by oral and intravenous route
}

\author{
Chattopadhyay P (1), Pandey A (1), Goyary D (1), Chaurasia A (1), Singh L (2), Veer V (1)
}

(1) Division of Pharmaceutical Technology, Defence Research Laboratory, Assam, India; (2) Department of Life Sciences, Defense Research Development and Organization, New Delhi, India.

\begin{abstract}
The toxicity of deoxynivalenol, both intravenously and orally, was investigated in male and female BALB/c mice. Technetium-99m ( ${ }^{99 \mathrm{~m}} \mathrm{Tc}$ )-labeled deoxynivalenol was administered to mice by tail vein injection and orally dosed. Distribution of labeled deoxynivalenol at 26 hours was monitored by gammascintigraphy. In the evaluated organs, the accumulation of radioactive deoxynivalenol was correlated with the amount of radioactivity. In addition, the toxicity of deoxynivalenol was measured by biochemical assays followed by histopathological findings. Kidney and hepatic marker enzymes were significantly increased in intravenously administered deoxynivalenol as compared to orally treated mice. Intravenously treated mice showed severe damage in liver and kidney when compared to those orally exposed. Biodistribution of ${ }^{99 \mathrm{~m} T c-}$ labeled deoxynivalenol differed between oral and intravenous treatment. In intravenously exposed mice, deoxynivalenol was distributed primarily in the liver and kidney whereas in oral exposure, it was found in the stomach and intestines after 26 hours. Deoxynivalenol toxicity, associated with its biodistribution and organ toxicity, was greatest where it had accumulated. The results show that the toxicity of deoxynivalenol is associated with organ accumulation.
\end{abstract}

Key words: technetium-99m ( ${ }^{99 \mathrm{~m} T c)}$, deoxynivalenol, biodistribution, toxicity, histopathology.

\section{INTRODUCTION}

Mycotoxins are biologically active secondary fungal metabolites of structurally diverse compounds produced by filamentous fungi. Contamination of foods and feeds with mycotoxins is a significant problem worldwide (1). Fusarium toxins zearalenone (ZON) and deoxynivalenol (DON) have been reported $(2,3)$. At present, more than 180 individual trichothecenes are described, with deoxynivalenol (DON) being the most frequent. Pharmacologically, the downregulation of immune function by $\mathrm{DON}$ has been well established in mouse and human lymphocytes (4). DON exerts pro-inflammatory effects by inducing cytokine and chemokine expression in mononuclear phagocytes. In mice, dietary exposure to DON up-regulates serum immunoglobulin A and also can lead to decreased concentrations of immunoglobulin $\mathrm{M}$ (IgM) and immunoglobulin G (IgG) in serum (5-8). DON is considered an important toxicant in agroterrorism. Several published works in the literature have reported toxicity of DON by the oral route. However, there have been no reports to date that indirect or direct exposure to DON via blood provokes such organ toxicity. The present investigation shows the comparison the organ toxicity of DON by the oral and intravenous routes.

\section{MATERIALS AND METHODS}

\section{Chemicals and Reagents}

Technetium-99m $\left.{ }^{{ }^{99} \mathrm{~m}} \mathrm{Tc}\right)$, obtained from the Board of Radioisotope Technology (BRIT), Bhabha Atomic Research Centre, Mumbai, India, 
was purchased from Sigma Chemicals (USA). Other chemicals used were of analytical reagent grade.

\section{Animals}

$\mathrm{BALB} / \mathrm{c}$ mice weighing 30 to $40 \mathrm{~g}$ were procured from the Laboratory of Animal Resources, Defence Research Laboratory, India, and were maintained in temperature-controlled rooms at the animal house with 12-hour alternating light and dark cycles and provided adequate nutrition and water ad libitum. For one week prior to experimentation, the animals were acclimatized at a room temperature of $24 \pm 2^{\circ} \mathrm{C}$ under a 12 hour light/dark cycle and $70 \%$ relative humidity relative humidity in the animal house.

All experimental protocols using animals were performed according to the "Principles of Laboratory Animal Care" (NIH publication 85-23, revised 1985) and approved by the Institutional Use and Care Committee. Twelve mice were divided into the oral $99 \mathrm{~m}$ Tc -labeled DON-treated group (I), which was administered $99 \mathrm{~m} \mathrm{Tc}$ - labeled DON orally $(10 \mu \mathrm{g} / \mathrm{kg}$ of body weight) $(\mathrm{n}=6)$, and the intravenous ${ }^{99 \mathrm{~m}}$ Tc-labeled DON-treated group (II), given ${ }^{99 m}$ Tc-labeled DON intravenously (10 $\mu \mathrm{g} / \mathrm{kg}$ of body weight) (n $=6$ ).

\section{Radio Labeling of DON}

For radio labeling of DON, the compound was mixed with ${ }^{99 \mathrm{~m}} \mathrm{Tc}$-pertechnetate $\left(\mathrm{TcO}_{4}^{-}\right)$in the presence of stannous chloride at $\mathrm{pH} 6.0$ followed by incubation for 30 minutes at room temperature (9). The radiochemical yield of ${ }^{99 \mathrm{~m} T c-D O T M P}$ was reported to be $>93 \%$ and confirmed by silica gel instant thin-layer chromatography. Purity of ${ }^{99} \mathrm{~m}$ Tc-DOTMP was determined and reported to be $>97 \%$. The specific activity of ${ }^{99 m}$ Tc-DOTMP was reported to be $185 \mathrm{MBq} / \mathrm{mmol}(5 \mathrm{Ci} / \mathrm{mmol})$.

The technetium-99m $\quad\left({ }^{99 \mathrm{~m}} \mathrm{Tc}\right)$-labeled deoxynivalenol was administered in mice by tail vein injection and dosed orally. After quality radio images were recorded with rapid clearance of background activity, all major organs were harvested from the animals at various time points starting at 2 hours to 26 hours after administration of the radiopharmaceutical.

\section{Biochemical Analysis}

Portions of liver and kidney were fixed in buffered $10 \%$ formalin solution for histopathological studies. Blood samples were obtained from the right ventricle via a left anterior thoracotomy at the time of sacrifice. The blood from the different mouse groups was collected in sterile syringes without anticoagulant and centrifuged to separate the serum to evaluate kidney and hepatic marker enzymes.

Liver marker enzymes - namely serum alanine transaminase (ALT) and aspartate transaminase (AST) - and kidney marker enzymes - including serum creatinine and blood urea - were estimated respectively by Merck kits (Merck India Ltd, India) according to the manufacturer's instructions.

After fixation in formalin (10\% phosphate buffered) and completion of the dehydration process, each paraffin embedded renal section $(4 \mu \mathrm{m})$ was stained by hematoxylin-eosin and examined in a light microscope (Olympus, Japan).

All values were expressed as mean \pm SD. Differences in mean values were compared using SPSS 11.0 by one-way ANOVA and StudentNewman-Keul (SNK) post-hoc test, in which $p$ $<0.05$ and $\mathrm{p}<0.01$ were considered statistically significant.

\section{RESULTS}

The distributions of ${ }^{99 \mathrm{~m}}$ Tc-labelled DON were evaluated in BALB/c mice after oral (OD) and intravenous (IV) administration. Sixty minutes after oral dosing, the radioactivity was detected primarily in the stomach, whereas after intravenous dosing the radioactivity was detected mainly in thekidneys. After threehours, maximum distributions were found in the stomach and kidney via OD and IV routes, respectively (data not disclosed by the investigators).

Furthermore, data obtained at 26 hours showed an accumulation of radioactivity in the liver and kidney by IV route whereas by OD route accumulation of maximum radioactivity was found in the intestine. Biodistribution by IV route shows interesting results. After 26 hours, the blood radioactivity was found to be five times higher than that of the oral route (Table 1, Figure 1).

After seven days of administration by IV route, glomerular size and the Bowman space increased compared to OD. Marked tubular dilation with cellular vacuolization was observed to be more abundant in IV group of mice than in the corresponding orally treated group (Figure 2 and Table 1). 
Table 1. Biodistribution of ${ }^{99 \mathrm{~m} T c}$-labeled DON

\begin{tabular}{c|c|c|c|c}
\hline \multirow{2}{*}{ Organ/tissue } & \multicolumn{4}{|c}{ Radioactivity of DON labeled with ${ }^{99 \mathrm{~m} T c}$} \\
\cline { 2 - 5 } & \multicolumn{2}{|c}{ Oral route after $\mathbf{2 6}$ hours } & \multicolumn{2}{c}{ Intravenous route after 26 hours } \\
\cline { 2 - 5 } & $\begin{array}{c}\text { Organ or blood } \\
\text { (weight or volume) }\end{array}$ & $\begin{array}{c}\text { DON present in } \\
\text { whole body }\end{array}$ & $\begin{array}{c}\text { Organ or blood } \\
\text { (weight or volume) }\end{array}$ & $\begin{array}{c}\text { DON present in } \\
\text { the whole body }\end{array}$ \\
\hline Blood & $2.20 \pm 0.53 \mathrm{~mL}$ & $0.055 \pm 0.008 \%$ & $2.35 \pm 0.66 \mathrm{~mL}$ & $2.65 \pm 0.58 \%$ \\
\hline Stomach & $95.12 \pm 2.36 \mathrm{mg}$ & $1.79 \pm 0.97 \%$ & $57.67 \pm 0.45 \mathrm{mg}$ & $0.27 \pm 0.006 \%$ \\
\hline Liver & $1238.29 \pm 77.84 \mathrm{mg}$ & $1.61 \pm 0.83 \%$ & $1750.44 \pm 89.65 \mathrm{mg}$ & $8.11 \pm 0.78 \%$ \\
\hline Intestine & $634.46 \pm 12.44 \mathrm{mg}$ & $1.76 \pm 0.79 \%$ & $727.81 \pm 32.40 \mathrm{mg}$ & $0.54 \pm 0.043 \%$ \\
\hline Kidney & $48.21 \pm 8.97 \mathrm{mg}$ & $0.06 \pm 0.002 \%$ & $56.40 \pm 8.69 \mathrm{mg}$ & $3.78 \pm 0.52 \%$ \\
\hline
\end{tabular}

Group orally treated with DON at 77590 counts per minute (CPM) versus 21715 for intravenous DON treatment (CPM). Other data are not disclosed by the investigators.
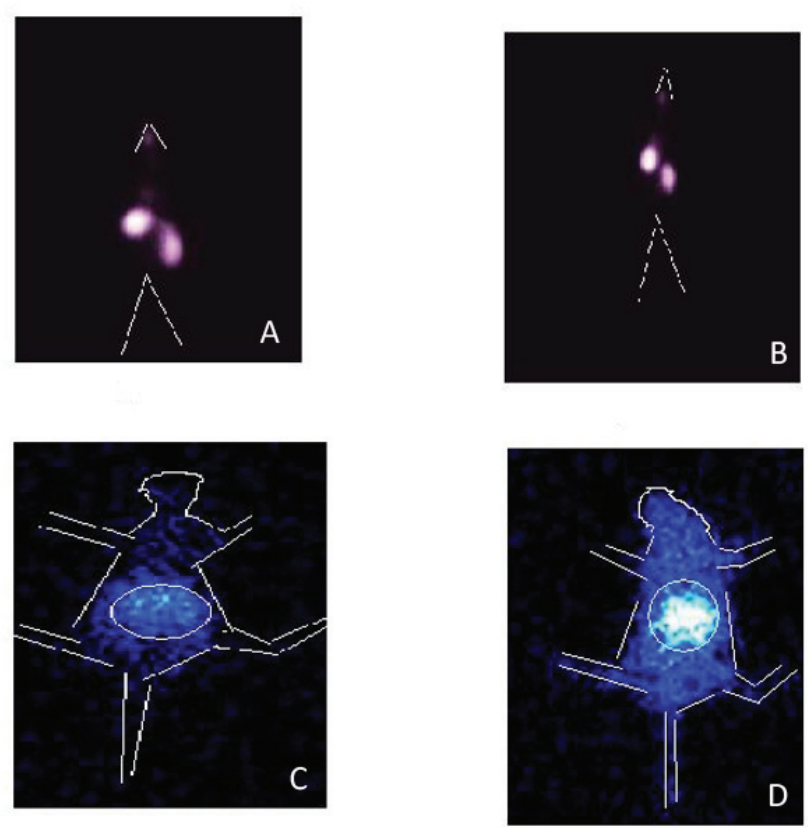

Figure 1. Organ distribution of Tc99m isotope labeled deoxynivalenol. (A) Photomicrograph at three hours after oral dosing. (B) Photomicrograph eight hours after oral dosing. (C) Photomicrograph 26 hours after oral dosing. (D) Photomicrograph 26 hours after IV dosing.

Effect of DON by oral route after seven days in liver shows few patchy spots of mild necrosis in various areas of centrilobular region. Acidophilic domains were observed in portal tracts. This impression was confirmed by a semi-quantitative analysis as livers with acidophilic domains usually had atrophy within those domains.

Seven days after intravenous administration of DON, severe liver damage and disarrangement of normal hepatic cells were present with intense centrilobular necrosis extending to mid zone as well as sinusoidal hemorrhages and dilation. There was infiltration of chronic inflammatory cells in the portal tracks. There was also extensive hepatocellular necrosis and sinusoidal congestion (Figure 2, Table 2).

The activity of kidney function enzymes such as serum creatinine, serum urea and BUN
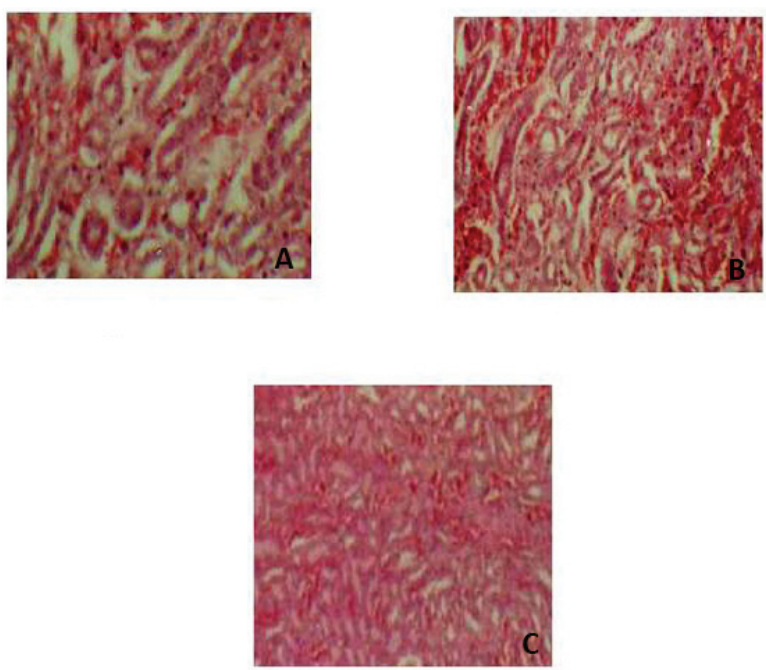

Figure 2. Hematoxylin and eosin (HE) stained kidney section (HE, 200x). (A) Mouse kidney section treated intravenously with DON shows inflammation and congestion after 26 hours. (B) Mouse kidney section treated intravenously with DON shows congestion and cytoplasmic vacuolization after seven days. (C) Mouse kidney section treated orally with DON shows mild inflammation after seven days. 
Table 2. Histopathological effect of DON on kidney after oral and intravenous administration

\begin{tabular}{c|c|c|c|c}
\hline \multirow{2}{*}{} & \multicolumn{2}{|c|}{ Oral route } & \multicolumn{2}{c}{ Intravenous route } \\
\cline { 2 - 5 } & After 26 hours & After 7days & After 26 hours & After 7 days \\
\hline Congestion & Absent & Mild & Mild & Severe \\
\hline Interstitial infiltrate & Absent & Mild & Absent & Severe \\
\hline Focal necrosis & Absent & Present & Absent & Severe \\
\hline Inflammation & Absent & Mild & Mild & Severe \\
\hline Glomerular size & No change & No change & No change & Increased \\
\hline Bowman space & No change & No change & No change & Increased \\
\hline $\begin{array}{c}\text { Cellular } \\
\text { vacuolization }\end{array}$ & Absent & Present & No change & Present \\
\hline
\end{tabular}

significantly increased $(\mathrm{p}<0.05)$ while total serum protein content activity was decreased ( $\mathrm{p}<$ $0.05)$ in mouse group intravenously treated with DON as compared to orally treated DON group of mice (Table 2).

The results shows that hepatic marker enzymes,
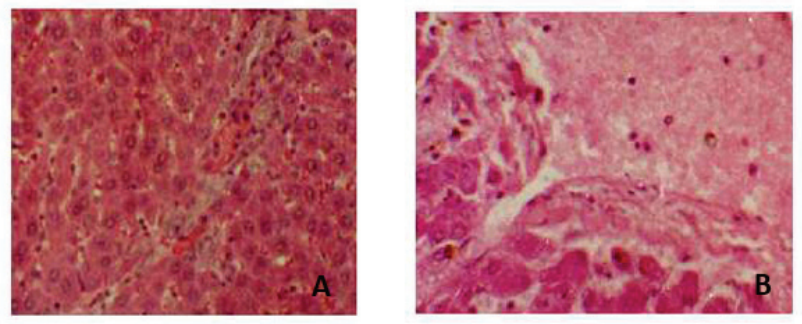

Figure 3. Hematoxylin and eosin (HE) stained liver section (HE, 200x). (A) Mouse kidney section treated intravenously with DON shows inflammation and congestion after 26 hours. (B) Intravenous DONtreated mouse kidney section shows congestion, cytoplasmic vacuolization after seven days.
SGPT and SGOT, were significantly increased ( $\mathrm{p}$ $<0.05)$ in mouse group treated intravenously with DON as compared to mice orally treated with DON (Table 4). Furthermore, ALP values were significantly increased $(p<0.05)$ in mice treated with DON intravenously in relation to those treated orally (Table 4) which indicates that DON is more toxic by IV than by OD route.

Values expressed as mean $\pm \mathrm{SD}, \mathrm{n}=6$. BUN: blood urea nitrogen; SGOT: serum gluatmic oxaloacetic transaminase; SGPT: serum gluatmic pyruvic transaminase activities; SAP: serum alkaline phosphatase; significantly different $\left({ }^{*} \mathrm{p}<\right.$ $\left.0.05,{ }^{* *} \mathrm{p}<0.01\right)$ from oral route after 26 hours.

\section{DISCUSSION}

In the present study, DON-treated mice developed severe toxicity whether administered orally or intravenously. The elevations in blood urea nitrogen, serum urea and creatinine suggested a significant kidney injury caused by DON. The intravenous route presented a higher

Table 3. Histopathological effect of DON on the liver after oral and intravenous administration

\begin{tabular}{c|c|c|c|c}
\hline \multirow{2}{*}{} & \multicolumn{2}{|c|}{ Oral route } & \multicolumn{2}{c}{ Intravenous route } \\
\cline { 2 - 5 } & After $\mathbf{2 6}$ hours & After 7days & After 26 hours & After 7 days \\
\hline Steatosis & Absent & Mild & Mild & Severe \\
\hline Inflammation and necrosis & Mild & Mild & Mild & Severe \\
\hline Nodular hyperplasia & Absent & Mild & Mild & Severe \\
\hline $\begin{array}{c}\text { Pyknotic, fragmented or absent } \\
\text { nucleus }\end{array}$ & No change & No change & No change & Present \\
\hline
\end{tabular}


Table 4. Effect of deoxynivalenol on hepatic function after oral and intravenous administration in BALB/C mice

\begin{tabular}{c|c|c|c|c}
\hline \multirow{2}{*}{} & \multicolumn{2}{|c|}{ Oral Route } & \multicolumn{2}{c}{ Intravenous route } \\
\cline { 2 - 5 } & $\begin{array}{c}\text { After 26 } \\
\text { hours }\end{array}$ & After 7days & After 26 hours & After 7days \\
\hline $\begin{array}{c}\text { Serum urea (mg/dL of } \\
\text { blood plasma) }\end{array}$ & $24.78 \pm 3.09$ & $33.10 \pm 2.59^{*}$ & $38.55 \pm 4.11^{* *}$ & $57.09 \pm 4.76^{* *}$ \\
\hline $\begin{array}{c}\text { Serum ureatinine (mg/dL } \\
\text { of blood plasma) }\end{array}$ & $0.45 \pm 0.09$ & $0.90 \pm 0.06^{*}$ & $0.66 \pm 0.08$ & $1.04 \pm 0.19^{* *}$ \\
\hline BUN (mg \%) & $19.67 \pm 2.81$ & $24.30 \pm 3.40^{* *}$ & $26.55 \pm 2.60^{* *}$ & $41.88 \pm 5.07^{* *}$ \\
\hline Total serum protein (g\%) & $5.69 \pm 0.94$ & $5.88 \pm 0.14$ & $4.22 \pm 0.81$ & $3.06 \pm 0.70^{* *}$ \\
\hline Blood sugar (mg\%) & $95.82 \pm 3.77$ & $110.87 \pm 10.76$ & $117.90 \pm 11.50^{*}$ & $95.82 \pm 3.77^{*}$ \\
\hline SGPT (IU/L) & $47.34 \pm 7.07$ & $50.99 \pm 5.10^{*}$ & $51.01 \pm 6.10$ & $55.66 \pm 8.42^{*}$ \\
\hline SGOT (IU/L) & $88.29 \pm 9.55$ & $92.20 \pm 9.55^{*}$ & $90.24 \pm 7.07$ & $97.55 \pm 6.07^{*}$ \\
\hline ALP (IU/L) & $259.88 \pm 23.41$ & $277.46 \pm 12.52^{* *}$ & $270.30 \pm 30.34^{* *}$ & $421.09 \pm 30.55^{* *}$ \\
\hline
\end{tabular}

degree of kidney severity than the oral route. Similarly, the degree of hepatic damage caused by DON intravenously was greater than by the oral route. This clinical finding corroborates histopathology studies. The presence of tissue damage was further substantiated by structural abnormalities in the kidney and liver. In addition, the ${ }^{99 \mathrm{~m} T \mathrm{Tc}}$-labeled DON biodistribution showed that maximum accumulation was effected in the stomach and intestine by the oral route versus the liver and kidney by the intravenous route. Therefore, the present study provides an indication that DON has low excretion and is prone to deposit in organs and may be a potential fungal toxin.

There are many studies suggesting that acute DON poisoning causes emesis, whereas chronic low-dose exposure elicits anorexia, growth retardation, immunotoxicity as well as impaired reproduction. Pathophysiological effects associated with DON include altered neuroendocrine signaling, proinflammatory gene induction, disruption of the growth hormone axis, and altered gut integrity. In a recent study, Königs et al. (10) showed that DON was neither metabolized by primary hepatocytes nor by the $\mathrm{HepG}_{2}$ cell line, while the present study affirms that DON provokes chronic toxicity as expressed by organ accumulation.

The authors suggested that DON might have contributed to tissue deposition which led to increases in liver and kidney damage. Furthermore, the study also showed the intravenous lethality of DON, while in another study, De Walle et al. (11) demonstrated a dual toxicological effect of DON on differentiated Caco- 2 cells consisting of an inhibition of protein synthesis as well as an increase in monolayer permeability. The toxicity of DON in domestic animals is well documented. A previous study showed that dietary contamination with various levels of deoxynivalenol (DON) and zearalenone (ZEA) in Ross 308 hybrid broilers produced higher levels of malondialdehyde (MDA) and glutathione peroxidase (GPx) in liver and kidney tissue in relation to the control group (12).

\section{CONCLUSIONS}

Our study provides support for the tissue accumulation of DON and organ toxicity of accumulated DON. Since DON is a common toxicant in cereal foods, there are major issues regarding the risks of acute poisoning and chronic effects posed to persons ingesting this trichothecene. A further challenge continues to be adopting procedures of best management of perceived risks without rendering critical food staples unavailable to an ever-expanding world population. Furthermore, regulatory guidelines should be imposed to mitigate the impact of this toxin on human health. 


\section{ACKNOWLEDGMENTS}

The authors are grateful to the Defence Research and Development Organization (DRDO), Ministry of Defence, Government of India for financial support.

\section{COPYRIGHT}

(c) CEVAP 2012

\section{SUBMISSION STATUS}

Received: September 2, 2012.

Accepted: March 29, 2012.

Abstract published online: April 5, 2012.

Full paper published online: August 31, 2012.

\section{CONFLICTS OF INTEREST}

The authors declare no conflicts of interest.

\section{FINANCIAL SOURCE}

Defence Research \& Development Organization (DRDO), Ministry of Defence, Government of India provided the financial grants.

\section{ETHICS COMMITTEE APPROVAL}

The present study was approved by the Institutional Animal Ethics Committee (IAEC) of the Defence Research Laboratory, Tezpur, Assam, India. Moreover, all experimental protocols using animals were performed according to the "Principles of Laboratory Animal Care" (NIH publication 85-23, revised 1985).

\section{CORRESPONDENCE TO}

Pronobesh Chattopadhyay, Division of Pharmaceutical Technology, Defence Research Laboratory, Assam, India. Email: chattopadhyay. drdo@gmail.com.

\section{REFERENCES}

1. Hussein HS, Brasel JM. Toxicity metabolism and impact of mycotoxins on humans and animals. Toxicology. 2001;167(2):101-34.

2. Kuiper-Goodman TP, Scott M, Watanabe H. Risk assessment of the mycotoxin zearalenone. Regul Toxicol Pharmacol. 1987;7(3):253-306.

3. Pestka JJ, Dong W, Warner RL, Rasooly L, Bondy GS, Brooks $\mathrm{KH}$. Elevated membrane $\operatorname{IgA}^{+}$and $\mathrm{CD}+(\mathrm{T}$ helper) populations in murine Peyer's patch and splenic lymphocytes during dietary administration of the trichothecene vomitoxin (deoxynivalenol). Food Chem Toxicol. 1990;28(6):409-20.

4. Atkinson HA, Miller K. Inhibitory effect of deoxynivalenol, 3- dcetyldeoxynivalenol and zearalenone on induction of mice and human lymphocyte proliferation. Toxicol Lett. 1984;23(2):21521.

5. Yan DH, Zhou R, Brooks KH, Pestka JJ. Role of macrophages in elevated IgA and IL-6 production by Peyer's patch cultures following acute oral vomitoxin exposure. Toxicol Appl Pharmacol. 1998;148(2):26173.

6. Pestka JJ. Deoxynivalenol-induced IgA production and IgA nephropathy-aberrant mucosal immune response with systemic repercussions. Toxicol Lett. 2003;140-141:287-95.

7. Forsell JH, Witt MF, Tai JH, Jensen R, Pestka JJ. Effects of 8-wk exposure of the B6C3F1 mouse to dietary deoxynivalenol (vomitoxin) and zearalenone. Food Chem Toxicol. 1986;24(3):213-9.

8. Pestka JJ, Casale WL. Naturally occurring fungal toxins. In: Hriaga JO, Simmons MS, editors. Food Contamination from Environmental Sources. New York: John Wiley \& Sons; 1990. p. 613-38.

9. Panwar P Chuttani K, Mishra P Sharma R, Modal A, Kumar Mishra A. Synthesis of trans-1,2cyclohexyldinitrilo tetramethylene phosphonic acid and its radiolabelling with $99 \mathrm{mTc}$ for the detection of skeletal metastases. Nucl Med Commun. 2006;27(8):619-26.

10. Königs M, Schwerdt G, Gekle M, Humpf N. Effects of the mycotoxin deoxynivalenol on human primary hepatocytes. Mol Nutr Food Res.2008;52(7):830-9.

11. De Walle JV, Sergent T, Piront N, Toussaint O, Schneider YJ, Larondelle Y. Deoxynivalenol affects in vitro intestinal epithelial cell barrier integrity through inhibition of protein synthesis. Toxicol Appl Pharmacol. 2010;245(3):291-8.

12. Borutova R, Faix S, Placha I, Gresakova L, Cobanova $\mathrm{K}$, Leng L. Effects of deoxynivalenol and zearalenone on oxidative stress and blood phagocytic activity in broilers. Arch Anim Nutr. 2008;62(4):303-12. 